\title{
Management of prolonged second stage of labor
}

\section{Sanjay Singh*, Uttara Aiyer Kohli, Shakti Vardhan}

Department of Obstetrics and Gynecology, Armed Forces Medical College, Pune, Maharashtra, India

Received: 01 May 2018

Accepted: 29 May 2018

\section{*Correspondence:}

Dr. Sanjay Singh,

E-mail: drsanjaysingh@gmail.com

Copyright: (c) the author(s), publisher and licensee Medip Academy. This is an open-access article distributed under the terms of the Creative Commons Attribution Non-Commercial License, which permits unrestricted non-commercial use, distribution, and reproduction in any medium, provided the original work is properly cited.

\section{ABSTRACT}

Second stage of labour has been often neglected leading to increased maternal and perinatal morbidity. Recognising and managing prolonged second stage is a challenge even to an experienced obstetrician. This article reviews the changes in the definition of prolonged second stage over the years. It discusses the causes, recognition and management options along with the difficulties in delivering a patient with prolonged second stage of labour. Though adding an extra hour to the definition of second stage in patients may reduce the rate of caesarean section but some studies also show a rise in maternal and perinatal morbidity. Obstetricians are familiarized to the different techniques of delivery of the impacted head. Once diagnosis of prolonged second stage is confirmed, causes should be identified and addressed, and treatment should be individualised, and timing and mode of intervention planned.

Keywords: Delivery of impacted head, Prolonged, Second stage of labor

\section{INTRODUCTION}

Human labour has been divided into four stages. First stage is characterized by painful uterine contractions and progressive cervical dilation until full dilation of the cervix.

The second stage is from the full dilatation of cervix till delivery of baby. The third stage is from delivery of the baby till the expulsion of the placenta and membranes. ${ }^{1} \mathrm{~A}$ fourth stage has also been added that includes the initial few hours after the expulsion of placenta.

Over the years emphasis has been laid on proper management and monitoring of the first stage of labour and active management of third stage of labour. Neonatal resuscitation protocols have also been laid out. However, the second stage of labour has often been neglected leading to birthing complications and perinatal morbidities.
Second stage may get unduly prolonged because of cephalopelvic disproportion (CPD), abnormal fetal position, and poor expulsive efforts resulting from conduction analgesia, sedation or maternal exhaustion.

Diagnosis and management of prolonged second stage of labour and its complications is difficult and often poses a dilemma to the treating obstetrician regarding timing and type of intervention.

Guidelines for diagnosing delay and its management have evolved over the years. Search for the best suitable definition, time limit and method of delivery such that both maternal and fetal outcomes are optimum continues. $^{2-8}$

This review article aims to analyze and interpret the current guidelines on management of prolonged second stage of labor and gives us some insight into what best we can do while handling such patients. 


\section{DISCUSSION}

2nd stage of labour starts with full dilation of cervix and ends after delivery of the fetus. As per NICE (National Institute for Clinical Excellence) guideline 2014 (CG190updated in 2017), second stage has been divided in two phases. ${ }^{1}$ First phase is Pelvic Phase, also known as Passive Phase or Phase of descent and the second phase is Perineal Phase also known as Active Phase or Expulsion Phase.

Pelvic phase is considered as an extension of first stage of labor that begins with full dilation of Cervix and ends after appearance of involuntary or spontaneous bearing down effort. This phase is characterized by rapid descent of the presenting part of the fetus. Fortunately, during this phase, the utero-placental perfusion and fetal oxygenation does not deteriorate. However, as we do not perform cervical assessment frequently, the beginning of this phase is difficult to define accurately and may lead to misinterpretation of the duration of second stage of labor.

Perineal phase begins with the appearance of 'bearing down' efforts and ends after delivery of the fetus. For the diagnosis of duration and prolongation of this phase correctly, timing of urge to push is to be noted carefully. Unlike pelvic phase utero-placental perfusion and fetal oxygenation start deteriorating in this phase thus undue prolongation of this phase may result in fetal hypoxia.

The median duration of second stage of labor as per Kilpatrick SJ et al is 50 minutes for primigravidas and 20 minutes for multigravidas. ${ }^{2}$ For two decades, average duration of 2 nd stage was considered as 2 hours for primigravidas and 1hour for multigravidas. This was based on the study done by Hellman et al in 1952, which showed that prolongation of this stage by more than 2 hours increases infant death rate by 2.5 folds. ${ }^{3}$ Later on in 1989, one extra hour was added to this timing by the ACOG (American Congress of Obstetricians and Gynecologists), for epidural analgesia. This was the consequence of a study conducted by Cohen et al in 1977, which suggested that epidural analgesia prolongs the duration of second stage. ${ }^{4}$

The latest ACOG recommendation for duration of second stage is $3+1$ hours (one hour for epidural analgesia) for primigravidas and $2+1$ hours (one hour for epidural analgesia) for multigravidas. ${ }^{5}$ ACOG \& NICHD (The National Institute of Child Health and Development) did this in 2012 with the premise that further prolongation of 2nd stage of labor will reduce the Caesarean section (CS) rate significantly. The NICHD and the ACOG convened a workshop in 2012 to brainstorm ways to reduce caesarean section rate. They reviewed several contemporary data till 2012 and concluded that longer second stage times should be allowed.

These conclusions were then incorporated into a Society of Maternal Fetal Medicine (SMFM) Obstetric Care
Consensus Report in 2014. To prospectively test this approach, Gimovsky AC et al in 2016, conducted a randomized control trial to assess the benefit of this recommended prolonged second stage definition in reduction of caesarean section rate and concluded that for every four nulliparous women left to extend their second stages for another hour, one caesarean section would be averted. $^{6}$ However its safety has been seriously questioned and has been challenged by several experts. Leveno KJ et al based on their experience of delivery of 29,991 patients delivered between 2003 and 2008 with prolonged second stage at Parkland Hospital; opine that prolonging second stage of labour will result in increased maternal \& neonatal complication. ${ }^{7}$

As per FIGO (Federation of International of Gynecologists and Obstetricians) 2012 recommendations primiparous women should not actively push for more than 2 hours and multiparous women for more than 1 hour, owing to an increased risk of birth asphyxia and maternal infection. ${ }^{8}$

As brought out by Leveno KJ et al and as per several other contemporary studies, prolonged second stage of labor is associated with several maternal and perinatal complications. ${ }^{7,9,10,11}$ Maternal complications include increased operative delivery, third and fourth degree perineal tear, post-partum hemorrhage and chorioamnionitis. Neonatal complications include low 5minute APGAR score, admission to the NICU, birth trauma and birth depression.

In a scenario where it is difficult to correctly diagnose the onset of second stage, there is controversy regarding duration and definition of prolonged second stage, there is an issue of maternal \& neonatal complications, what should one do? Probably the best answer is, "Individualize the case". As long as there is adequate progression of labor and there is no maternal and fetal compromise, it is needless to stick to a predetermined fixed time frame. ${ }^{12}$

What are the causes of prolonged 2nd stage? Second stage may get unduly prolonged because of contracted pelvis, large fetus, cephalopelvic disproportion (CPD), abnormal fetal position like occipitoposterior (OP), occipitotransverse (OT) and mentoposterior position and poor expulsive efforts resulting from conduction analgesia, sedation or maternal exhaustion. ${ }^{13,14}$

Abnormal descent pattern leads to prolongation of 2 nd stage and needs intervention. This is of two typesprotracted descent and arrest of descent. Protracted descent is defined as descent of presenting part by $<2 \mathrm{~cm} /$ hour for multiparous women and $<1 \mathrm{~cm} /$ hour for primiparous women, whereas arrest of descent is defined as no descent of the presenting part for $>$ one hour. Both may be an indicator of obstructed labour that needs prompt intervention. ${ }^{8,9}$ 
Can we prevent delay in second stage? As per RCOG (Royal College of Obstetricians and Gynaecologists) guideline 2011, continuous support during labour and allowing birthing companion, use of nonsupine position e.g. upright or lateral position, avoiding epidural analgesia, delayed pushing in primiparous women with epidural and use of oxytocin for primis under epidural analgesia, has been found helpful in preventing delay in second stage.

What should one do once 2 nd stage has been found to be prolonged? Once one encounters delay or prolongation of the second stage, a prompt and thorough clinical assessment to rule out full bladder, cephalo-pelvic disproportion, malpresentation of the fetal head, e.g. OP, OT, or deflexed fetal head, inadequate uterine activity, poor pushing effort and signs of obstructed labor should be done. Targeted treatment may then be offered to the patients. $^{14}$

Oxytocin plays an important role in management of prolonged second stage. As per NICE guideline 2014, Oxytocin may be considered in primiparous women under epidural if contractions are inadequate at the onset of second stage. This has been found to reduce the need for operative delivery. ${ }^{1}$ However, as per RCOG guideline 2011, extreme caution should be exercised in multigravida patients for fear of rupture of uterus because of undiagnosed CPD.

Vacuum and forceps are useful tools for conduction of vaginal delivery in prolonged second stage in indicated cases like, presumed fetal compromise, to shorten and reduce the effects of the second stage of labour on medical conditions (e.g. cardiac disease Class III or IV, hypertensive crises, myasthenia gravis, spinal cord injury, proliferative retinopathy), inadequate progress in second stage and maternal fatigue/exhaustion.

RCOG guidelines 2011 give an exhaustive list of certain basic principles and guidelines for safe conduction of instrumental deliveries. Few of them are: Consent is must for operative delivery. A trial of operative vaginal births should be done only in operation theatre. Operative vaginal delivery should be abandoned in case there is no evidence of progressive descent and where delivery is not imminent following three contractions/pulls. The use of sequential instruments is associated with an increased risk of trauma to the infant and thus is not preferred. Assessment of caput and moulding, station, position and rotation of head is important for correct application of the instrument to reduce the risk of failure. ${ }^{15}$

OP position is an important cause of prolonged second stage. Prolonged labor in OP position leads to formation of big caput resulting in several problems. Firstly, assessment of station may be wrong and for correct assessment of the station one has to perform Leopald maneuver three and four abdominally. Secondly, the assessment of position may also be erroneous as suture lines are not well palpable because of the big caput. In this situation palpation of unfolded pinna will give the direction of the occiput. Thirdly, the big caput causes gaping of perineum and premature bearing down effort when the head is still high in the pelvis, giving a false sense of advanced labor. Finally, it leads to difficulty in application of vacuum/forceps that increases the risk of failure. In direct occipito posterior position the fetal head is delivered by face to pubis: firstly, by flexion and then by extension. Thus, if one applies vacuum/forceps for the delivery, the pull of the instrument has to be in the correct direction.

How to conduct the delivery of a fetus lying in occipitoposterior position? In 2/3rd cases of OP position, with good uterine contractions and bearing down effort, head rotates to $3 / 8$ th of a circle and normal vaginal delivery occurs without much of a problem. However, in $1 / 3$ rd of cases, where the head fails to rotate or rotates incompletely, anteriorly or posteriorly, second stage may get prolonged and complications during delivery may take place. If the occiput rotates posteriorly to 1/8th of the circle, it leads to direct occipito posterior position (DOP). In adequate pelvis (e.g. anthropoid or gynecoid) with good uterine contractions and bearing down effort face to pubis delivery takes place.

But in case where DOP arrest takes place, instrumental delivery or cesarean section (CS) is required. If the head rotates anteriorly only by $1 / 8$ th of a circle it causes deep transverse arrest (DTA). In this scenario one may rotate the head manually or by rotational forceps (Kielland Forceps) followed by delivery of the head either by vacuum or by forceps application. In case one is not confident with rotational forceps, CS may be performed. Similar tactics may be applied for the head that has failed to rotate and has led to oblique occipitoposterior arrest (OOP).

Second stage CS 'especially for a deeply engaged head' is a night mare for all obstetricians. It entails complications that one must know of and be prepared to combat during CS. These include: bladder injury while opening up of abdomen, difficulty in delivery of head, lateral extension of the angle causing broad ligament hematoma, tear of lower uterine segment (LUS) \&downward extension of scar that may involve bladder, difficulty in tracing retracted LUS after surgery for which one may take a stay suture earlier, accidental incision over vagina, post-partum hemorrhage $(\mathrm{PPH})$, puerperal infection and later fistula formation and pelvic organ prolapse (POP). ${ }^{16}$

Delivery of deeply engaged head is a challenge. There have been two techniques described for this purpose. Push technique \& Pull Technique. ${ }^{17-20}$ An innovative method is to use fetal pillow. In push technique an assistant is required to push the head of the fetus from below after uterine incision has been given. In pull 
technique however, the limbs and trunk of the baby are delivered before delivery of the head.

Based on position of the back-pull technique may be of 3 types. For back lying anteriorly, Patwardhan maneuvre is used wherein both shoulders are delivered first followed by delivery of the trunk by flexion, then the legs are delivered and finally head is lifted out. For back lying posteriorly, reversed breech extraction is performed wherein both legs are delivered first followed by delivery of trunk by flexion, then both shoulders are delivered and finally head is lifted out. In OT position anterior shoulder is delivered first followed by delivery of the posterior shoulder, then trunk is delivered by flexion followed by legs and finally the head is lifted out.

The Fetal Pillow is an innovative device invented by Dr Rajiv Varma in 2007 for dis-impaction of the deeply engaged fetal head. It is a soft silicone balloon device that is inserted below the baby's head and inflated using saline with a syringe. It inflates only in one direction and elevates the head. ${ }^{21}$

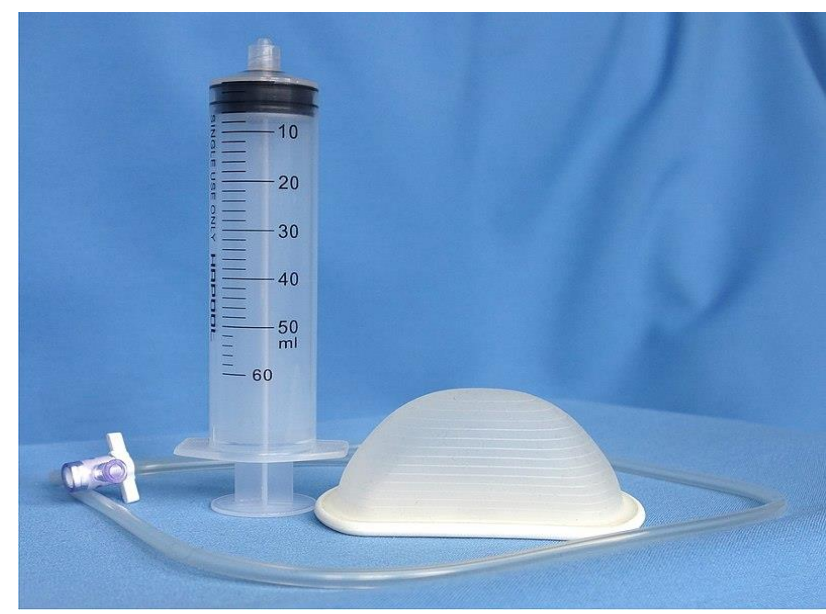

Figure 1: Fetal pillow used for disengagement of head during second stage cesarean section with deeply engaged head.

\section{CONCLUSION}

To conclude, diagnosing and managing prolonged second stage of labor is challenging. We must individualize care of patients with second stage prolongation. In the absence of any complications we may wait longer as per the newer definitions, however if fetal compromise is suspected or other features point towards cephalo-pelvic disproportion or malposition as cause of undue prolongation intervention earlier is justified.

Prolonged second stage may be managed by oxytocin augmentation, instrumental delivery or caesarean section. Delivery of a deeply impacted head may pose a problem even during caesarean section. Skilled birth attendants and experienced obstetricians should conduct these deliveries.
Funding: No funding sources

Conflict of interest: None declared

Ethical approval: Not required

\section{REFERENCES}

1. NICE clinical guidelines. Intrapartum care for healthy women and babies. Clinical guideline no: CG190. Published date: December 2014. Last updated: February 2017

2. Kilpatrick SJ, Laros Jr RK. Characteristics of normal labor. Obstet Gynecol. 1989 Jul;74(1):85-7.

3. Hellman LM, Prystowsky H. The duration of the second stage of labor. Am J Obstet Gynecol 1952;63:1223-33.

4. Cohen WR. The influence of the duration of second stage of labor on perinatal outcome and puerperal morbidity. Obstet Gynecol. 1977;49:266-269.

5. Caughey AB, Cahill AG, Guise JM, Rouse DJ. Safe prevention of the primary cesarean delivery. Am J Obstet Gynecol. 2014 Mar 1;210(3):179-93.

6. Gimovsky AC, Berghella V. Randomized control trial of prolonged second stage: Extending the time limit vs usual guidelines. Am J Obstet Gynecol 2016;214:361.e1-6.

7. Leveno KJ, Nelson DB, McIntire DD. Second stage labor: How long is too long? Am J Obstet Gynecol 2016;214:484-489.

8. FIGO Safe Motherhood and Newborn Health (SMNH) Committee (2012). Management of the second stage of labor. Int $\mathrm{J}$ Gynecol Obstet. 119:111-6.

9. Le Ray C, Audibert F, Goffinet F, Fraser W. When to stop pushing: effects of duration of second-stage expulsion efforts on maternal and neonatal outcomes in nulliparous women with epidural analgesia. Am J Obstet Gynecol. 2009 Oct 1;201(4):361-e1.

10. Myles TD, Santolaya J. Maternal and neonatal outcomes in patients with a prolonged second stage of labor. Obstet Gynecol. 2003 Jul 1;102(1):52-8.

11. Allen VM, Baskett TF, O'Connell CM, McKeen D, Allen AC. Maternal and perinatal outcomes with increasing duration of the second stage of labor. Obstet Gynecol. 2009 Jun 1;113(6):1248-58.

12. Cheng YW, Shaffer BL, Nicholson JM, Caughey $\mathrm{AB}$. Second stage of labor and epidural use: a larger effect than previously suggested. Obstet Gynecol. 2014 Mar 1;123(3):527-35.

13. Menticoglou SM, Manning F, Harman C, Morrison I. Perinatal outcome in relation to second-stage duration. Am J Obstet Gynecol. 1995 Sep 1;173(3):906-12.

14. Willington L, Angus S, Fleet J, Goodeve M, McKay $\mathrm{H}$, McKendrick L, et al. Perinatal practice guideline analgesia for labour and birth (Pharmacological).

15. Royal College of Obstetricians and Gynaecologists. Green-top Guideline No. 26: Operative vaginal delivery.London: RCOG; 2011.

16. Vousden N, Cargill Z, Briley A, Tydeman G, Shennan AH. Caesarean section at full dilatation: 
incidence, impact and current management. The Obstet Gynaecol. 2014 Jul 1;16(3):199-205.

17. Jeve YB, Navti OB, Konje JC. Comparison of techniques used to deliver a deeply impacted fetal head at full dilation: a systematic review and metaanalysis. BJOG. 2016;123:337-45.

18. Fong YF, Arulkumaran S. Breech extraction-an alternative method of delivering a deeply engaged head at cesarean section. Int $\mathbf{J}$ Gynaecol Obstet. 1997;56(2):183-4.

19. Chopra S, Bagga R, Keepanasseril A, Jain V, Kalra J, Suri V. Disengagement of the deeply engaged fetal head during cesarean section in advanced labor: conventional method versus reverse breech extraction. Acta Obstet Gynecol Scand2009; 88:1163-6.

20. Singh M, Varma R. Reducing complications associated with a deeply engaged head at caesarean section: a simple instrument. The Obstet Gynaecol. 2008;10:38-41.

21. Clinical Innovations. Murray Utah. C-snorkel: Impacted Fetal Head Release Device by Softlift. 2012.

Cite this article as: Singh S, Kohli UA, Vardhan S. Management of prolonged second stage of labor. Int J Reprod Contracept Obstet Gynecol 2018;7:252731 . 